\title{
On-site vibration test and dynamic response analysis of wind turbine of intertidal zone
}

\author{
Shuai Huang ${ }^{1}$, Yuejun Lyu ${ }^{2}$, Yanju Peng ${ }^{3}$, Haijun Sha ${ }^{4}$ \\ Institute of Crustal Dynamics, China Earthquake Administration, 100085, Beijing, China \\ ${ }^{1}$ Corresponding author

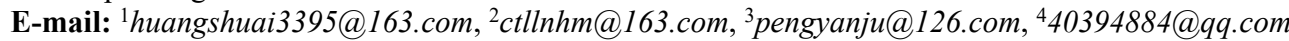

Received 16 September 2019; accepted 7 October 2019

DOI https://doi.org/10.21595/vp.2019.21020

Check for updates

Copyright $(0) 2019$ Shuai Huang, et al. This is an open access article distributed under the Creative Commons Attribution License, which permits unrestricted use, distribution, and reproduction in any medium, provided the original work is properly cited.

\begin{abstract}
In our study, the vibration signal of impulse response and attenuation response are extracted using the correlation function and power spectrum, and the natural frequency of wind turbine is determined. Compared with the rotation frequency of the blades of wind turbine which are $1 p$ (one blade) and $3 p$ (three blades), and wind vibration performance of the wind turbine is determined. The natural frequency of wind turbine is between the frequencies of one blade and three blades of wind turbine, which can avoid resonance phenomenon and meet the precision requirement for engineering application. The laws of acceleration and strain response along the wind turbine under ordinary wind load are obtained by installing acceleration sensor and strain gauge along the wind turbine. We found that the acceleration at the wind turbine top increases 10 times than that at the bottom. The acceleration influenced by tide is 1.14 times than that with no tide. The strain produced maximum value at the opening place of wind turbine and near the top, it should be paid attention in the engineering design.
\end{abstract}

Keywords: wind turbine, online field monitoring, impulse response, natural frequency.

\section{Introduction}

Rapid development of wind energy in seismically active regions like China requires evaluation of design seismic load of wind turbine structures to ensure structural integrity. Wind turbine presents a large inertial mass at the top and a rotating component around a horizontal axis. Wind turbines are vulnerable to wind loadings, and the identification of their actual dynamic properties is a crucial step in understanding its dynamic behavior. That is necessary to improve design guidelines and to predict the structural behavior under any expected future loading. Wind turbine is mainly influenced by the wind load However, the dynamic loads produced by the rotation of the wind turbine blade and wind load are very complex. It is very necessary to investigate the dynamic characteristics of wind turbine and important to assure the safety of the structure under extended service. Thus, monitoring the wind turbine is very significant for determining the dynamic characteristics of the structure.

Environment of wind turbine structure is very complex (located on mountains or in sea), and it often faces major disasters. How to ensure the security of the structure has been studying by scholars. N. Bazeos etc. [1] (2002) studied the static loads, seismic response and stability of wind turbine. Baumgart A. [2] (2002) studied the dynamic response of wind turbine structure under the wind load. Lymon. [3] (2008) and Pekka [4] (2008) introduced the design method of foundation of wind turbine. Zhou Bo [5] (2004) investigated the dynamic responses and influencing factors of the wind turbine using finite element analysis. Kou Guo [6] (2004) conducted the wind tunnel test of the wind turbine structure. However, the studying of wind turbine is more focused on the theoretical analysis and numerical simulation at home and abroad and less to carry out the in-site monitoring of wind turbine. The study of large-scale wind turbine structure is still in the exploratory stage in china. Thus, in-site monitoring of wind turbine is carried out to determine the dynamic response of wind power, and provides guidance for the security service of wind turbine. 


\section{Monitoring of wind turbine}

\subsection{Project profile}

Take a wind turbine in the land-ward of the South Yellow Sea as the monitoring object, as shown in Fig. 1. Engineering area has a marked continental monsoonal climate, and wind direction varies with the seasons. North wind is more popular in winter, and wind direction dramatic changes in spring. The average tide level is $4.6 \mathrm{~m}$, and the effective wave height is about $0.3 \mathrm{~m}$, and the average period of the effective wave ranges from $4.0 \mathrm{~s}$ to $4.9 \mathrm{~s}$.

\subsection{Monitoring equipment}

Monitoring instruments include the strain monitoring equipment and the Acceleration monitoring equipment. The strain monitoring equipment are including strain gauge, wires, dynamic strain indicator, data collecting instrument and wind speed sensor. The Acceleration monitoring equipment are including charge amplifier and acceleration sensor. Monitoring instruments are shown in Fig. 1. Location of monitoring points is mainly paced in each platforms of wind tower along the height of the wind turbine. The arrangements of monitoring points outside and inside the wind turbine are shown in Fig. 2. The monitoring points are divided into 5 groups, the strain monitoring points are four and acceleration monitoring points are two, as shown in Fig. 3.

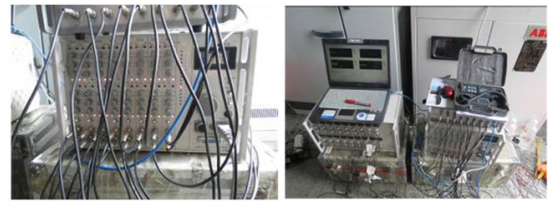

Fig. 1. Monitoring equipment

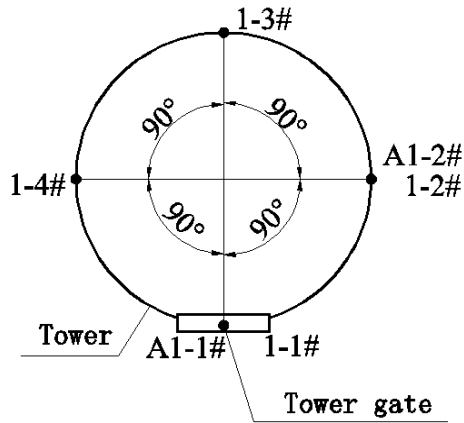

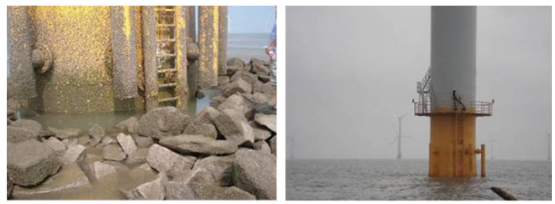

Fig. 2. Pile foundation of wind turbine

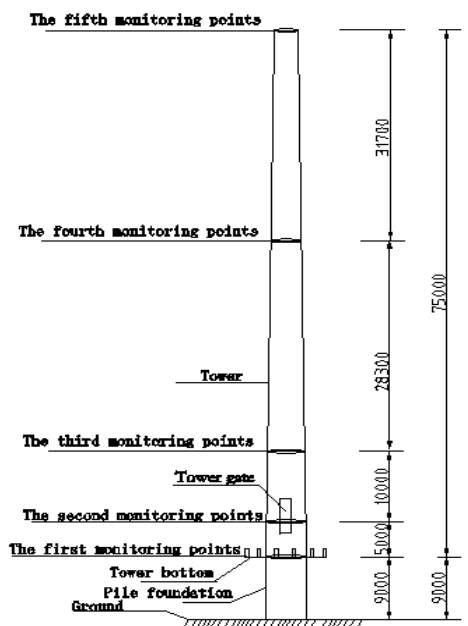

Fig. 3. Monitoring points distributions

\section{Natural frequencies test of wind turbine}

For obtaining the natural frequency of the wind turbine, when the running speed of wind turbine blades reduce to $3.0 \mathrm{rpm}$, break the wind turbine blades, which means to impose a pulse force, then collect the vibration signals of the wind turbine. The acceleration sensors were set at the top of wind turbine. When the wind turbine was first braked. The Acceleration value at the top 
was shown in Fig. 4, and the attenuation Fourier frequency was shown in Fig. 5.

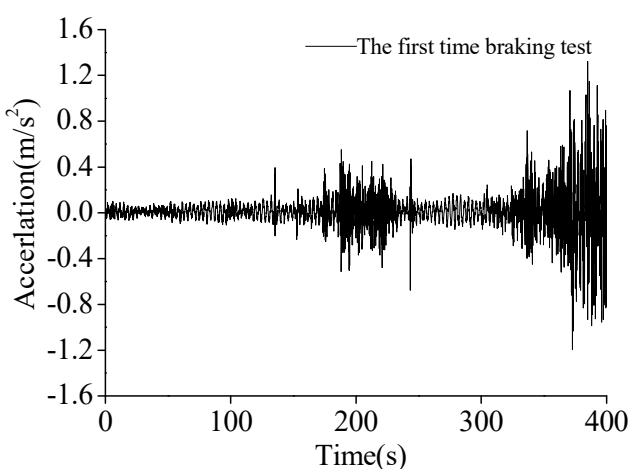

Fig. 4. Acceleration value

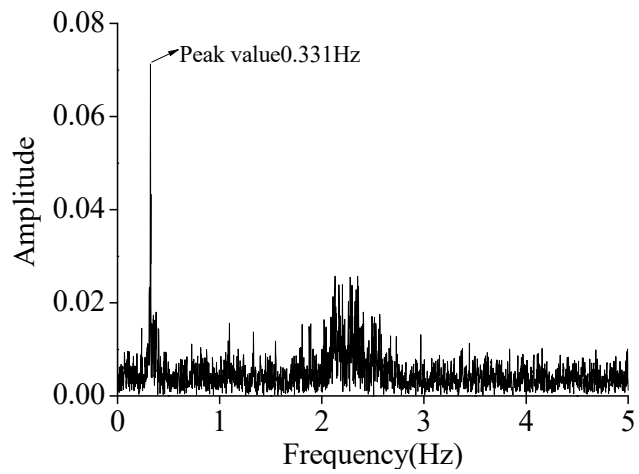

Fig. 5. Attenuation Fourier frequency

The wind turbine was applied the second brake, the accelerations at the top of wind turbine were shown in Fig. 6, and the attenuation Fourier frequencies were shown in Fig. 7.

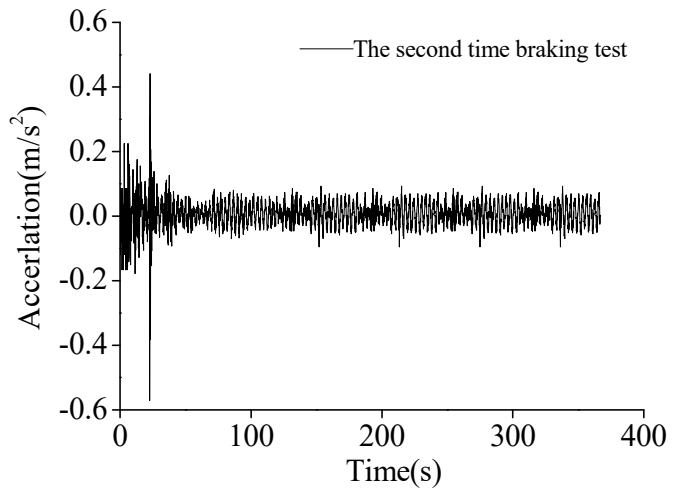

Fig. 6. Acceleration value

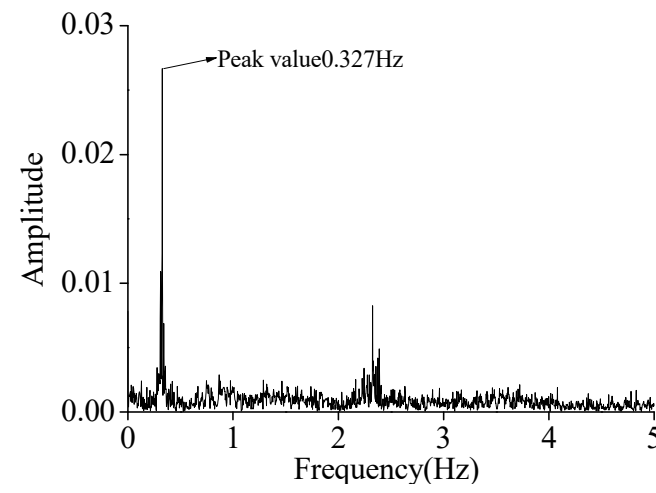

Fig. 7. Attenuation Fourier frequency

According to the natural frequency of vibration test of the wind turbine, the first natural frequency was shown in Table 1.

We can see from Table 1, the natural frequencies obtained from the first and second tests are $0.331 \mathrm{~Hz}$ and $0.327 \mathrm{~Hz}$. The period of wind turbine obtained from the first and second tests are $3.021 \mathrm{~s}$ and $3.058 \mathrm{~s}$. Further compared with the frequencies of one blade and three blades of wind turbine which are $0.22 \mathrm{~Hz}$ and $0.66 \mathrm{~Hz}$, the natural frequency of wind turbine is between the frequencies of one blade and three blades of wind turbine, which can avoid resonance phenomenon and meet the precision requirement for engineering application.

Table 1. Natural frequency of wind turbine

\begin{tabular}{|c|c|c|c|c|}
\hline Test & Natural frequency (Hz) & $\begin{array}{c}\text { Frequency of one } \\
\text { blade }(\mathrm{Hz})\end{array}$ & $\begin{array}{c}\text { Frequency of three } \\
\text { blades }(\mathrm{Hz})\end{array}$ & Period (s) \\
\hline The first test & 0.331 & 0.22 & 0.66 & 3.021 \\
\hline The second test & 0.327 & 0.22 & 0.66 & 3.058 \\
\hline
\end{tabular}

\section{Dynamic response of wind turbine}

\subsection{Acceleration test}

Select the field monitoring data of the main vibration direction of the wind turbine and the 
finite element simulation analysis results are shown in Fig. 8 to Fig. 13.

As shown in Fig. 8 to Fig. 13, with the height increasing, the maximum acceleration at the bottom of the wind turbine is $0.005 \mathrm{~m} / \mathrm{s}^{2}$, while the maximum acceleration at the top of wind power is $0.051 \mathrm{~m} / \mathrm{s}^{2}$, which increases 10 times, and it shows that the wind turbine exists obvious amplification at the top of wind turbine, especially pay more attention to vibration of the wind turbine top influence by strong wind. Compared the monitoring results with the finite element simulation, and the maximum deviation is about $25 \%$, which is within the allowable range. The accelerations of main vibration direction with no tide and high tide level are shown in Fig. 13, and the acceleration with no tide level at the wind turbine top is $0.792 \mathrm{~m} / \mathrm{s}^{2}$, and the acceleration with the high tide level at the wind turbine top is $0.901 \mathrm{~m} / \mathrm{s}^{2}$, which is 1.14 times than that with no tide. Thus, the influence of wave load to wind turbine should be considered when the wind turbine is designed.

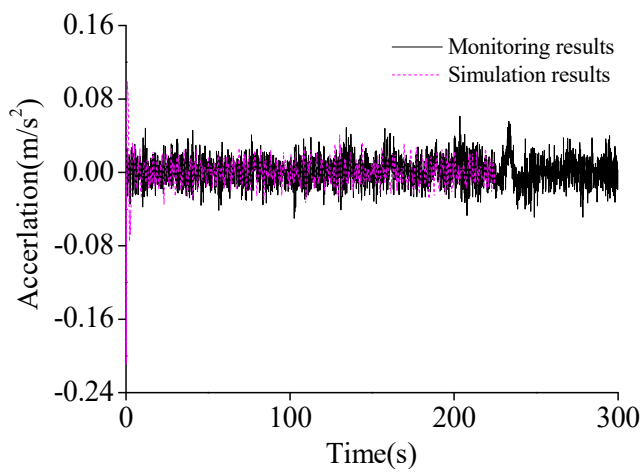

Fig. 8. Acceleration value of A5-2

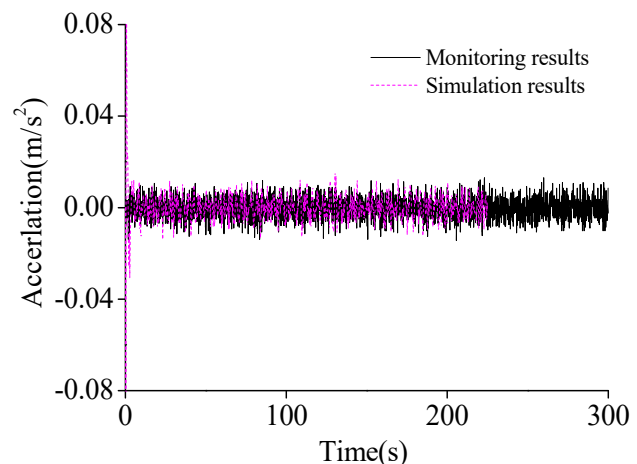

Fig. 10. Acceleration value of A3-2

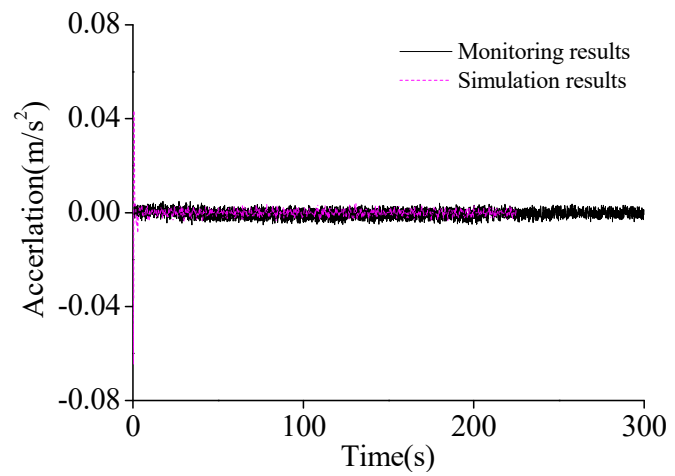

Fig. 12. Acceleration of A1-2

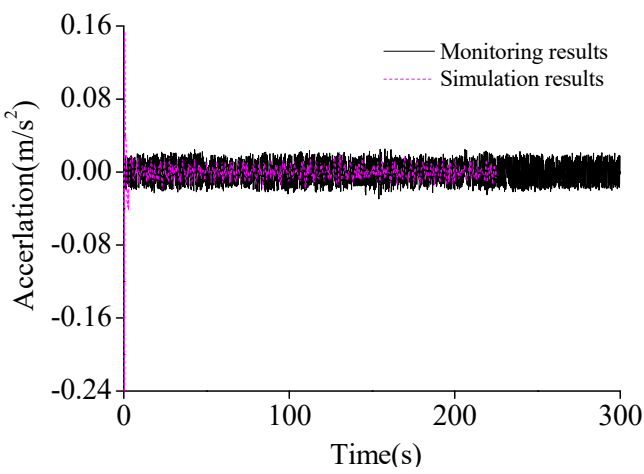

Fig. 9. Acceleration value of A4-2

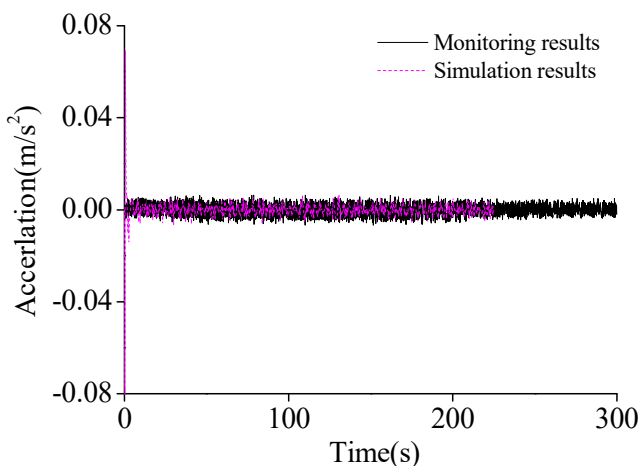

Fig. 11. Acceleration value of A2-2

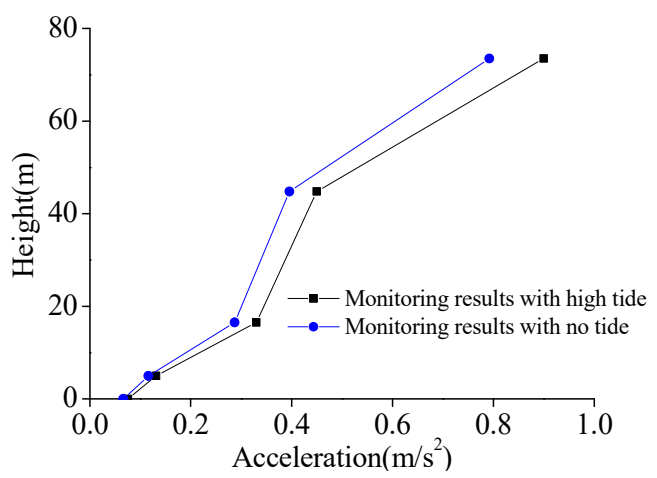

Fig. 13. Acceleration along the height 


\subsection{Strain monitoring of wind turbine}

The arrangement of strain monitoring points is shown in Fig. 14, and strain values along the height of the wind turbine are shown in Fig. 14 to Fig. 16.
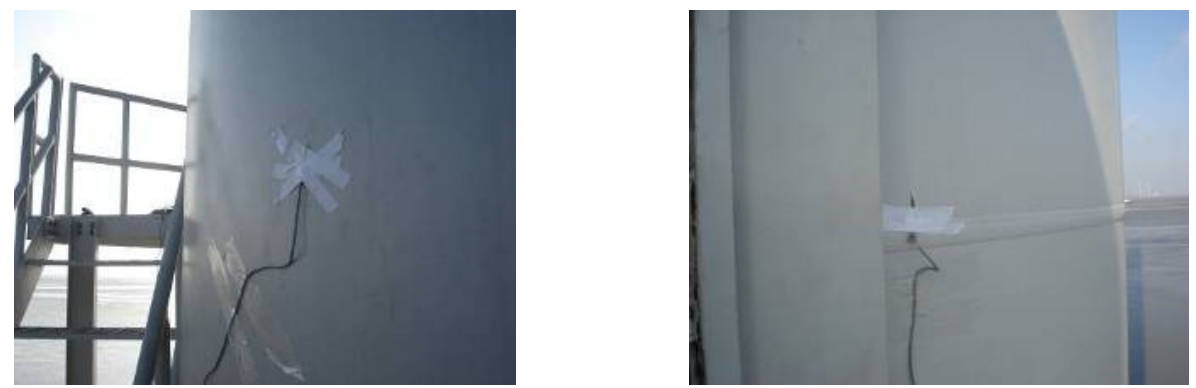

Fig. 14. The arrangement of strain monitoring points
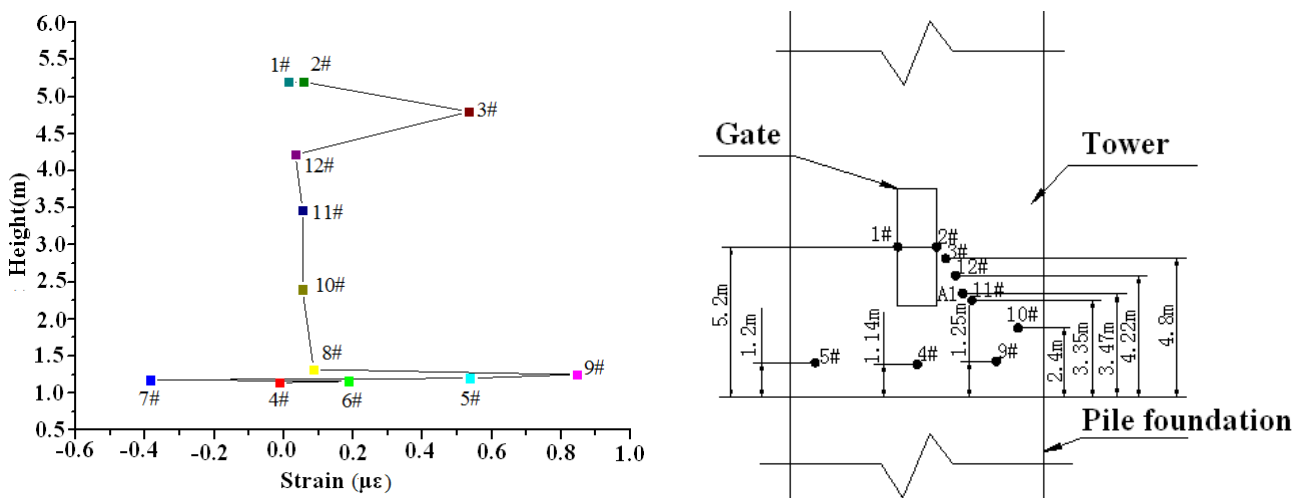

Fig. 15. Strain values along the height of the wind turbine influenced by wind speed $0-2 \mathrm{~m} / \mathrm{s}$
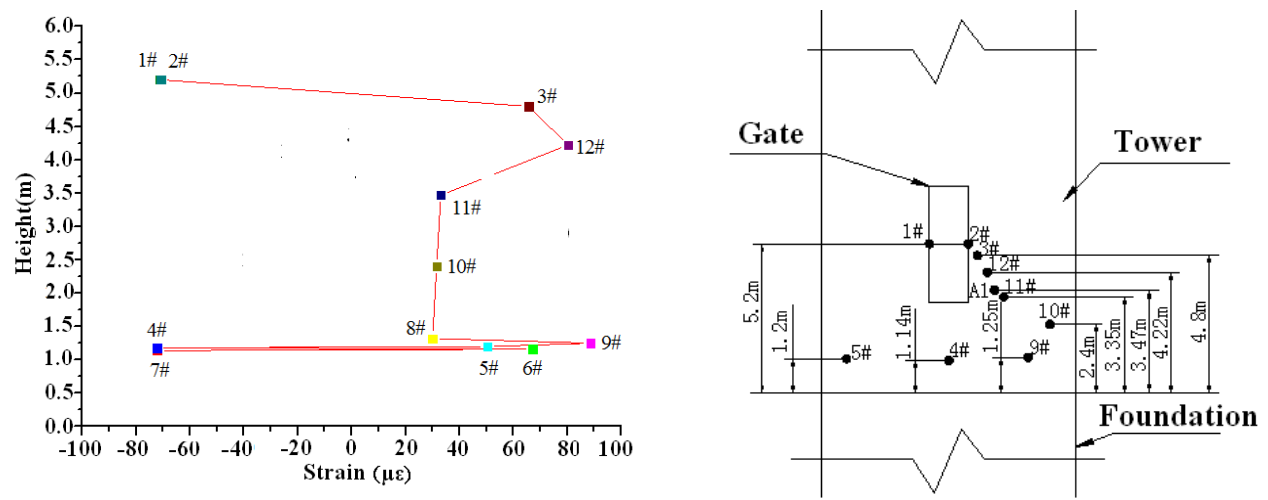

Fig. 16. Strain values along the height of the wind turbine influenced by wind speed $6-8 \mathrm{~m} / \mathrm{s}$

We can see from Fig. 14 to Fig. 16, the maximum strain values obtained by the field monitoring are $0.95 \mu \varepsilon$ and $92 \mu \varepsilon$ under wind load whose speed are $0-2 \mathrm{~m} / \mathrm{s}$ and $6-8 \mathrm{~m} / \mathrm{s}$. With the height increasing along the wind turbine, the maximum strains show the tendency of increasing-decreasing-increasing-decreasing, and the strain produced maximum value at the opening place of wind turbine. We find that the opening place of the wind turbine produces stress concentration. Due to the existence of the engine room which produces the eccentric load, wind turbine produces the larger strain value near the top. There are two methods to reinforce the wind 
turbine wall near the top. First, the wind turbine wall thickness should be increased; secondly, the stiffeners should be added at top position. Thus, the top position of the wind turbine should be paid attention in the engineering design.

\section{Conclusions}

1) The vibration signal of impulse response and attenuation response are extracted, and obtained the natural frequency of wind turbine. Then compared with the rotation frequency of the blades of wind turbine which are $1 p$ (one blade) and $3 p$ (three blades), it shows that he natural frequency of wind turbine is between the frequencies of one blade and three blades of wind turbine, which can avoid resonance phenomenon and meet the precision requirement for engineering application.

2) With the height increasing along the wind turbine, acceleration values show the tendency of increasing, and the acceleration at the top increases 10 times than that at the bottom. The acceleration influenced by tide is 1.14 times than that with no tide. Thus, the influence of wave load on wind turbine should be considered.

3) With the height increasing along the wind turbine, the maximum strains show the tendency of increasing-decreasing-increasing-decreasing, and the strain produced maximum value at the opening place of wind turbine due to the stress concentration. As the existence of the engine room which produces the eccentric load, wind turbine produces the larger strain value near the top, and it should be paid attention in the engineering design.

\section{Acknowledgements}

This work is financially supported by the National Key R\&D Program of China (2017YFC1500404), National Natural Science Foundation of China (Grant No. 51708516), and research grant from Institute of Crustal Dynamics, China Earthquake Administration (No. ZDJ2019-10).

\section{References}

[1] Bazeos N., Hatzigeorgiou G. D. Static seismic and stability analyses of a prototype wind turbine steel tower. Engineering Structures, Vol. 4, 2002, p. 1015-1025.

[2] Baumgart A. A mathematical model for wind turbine blades. Sound Vibration, Vol. 251, 2002, p. 1-12.

[3] Reese Lymon C., Wang Shin Tower Design of foundations for a wind turbine employing modern principles. Research to Practice in Geotechnical Engineering Congress, 2008, p. 351-365.

[4] Pekka Maunu Design of Wind Turbine Foundation Slabs. Alulae University of Technology, 2008, p. 128.

[5] Zhou Bo, Fei Chaoyang, Chen Changzhen Study on vibration characteristics of the tower for wind turbine. Journal of Vibration Engineering, Vol. 17, 2004, p. 903-905.

[6] Xu Heyong, Ye Zhengyin, Wang Gang, Shi Aiming Numerical simulation of rotor forward flight flow based on the unstructured dynamic patched grid. Acta Aerodynamica Sinica, Vol. 9, 2004, p. 311-318. 